\title{
A Tribute to Professor Dulitha N Fernando - Teacher, Mentor and Colleague
}

DOI: https://doi.org/10.4038/jccpsl.v27i1.8454

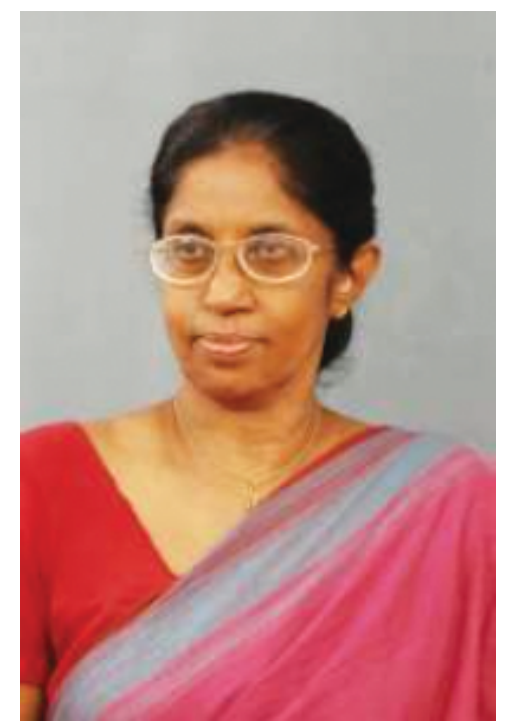

Emeritus Professor Dulitha Nandanie Fernando's academic journey was an extremely colourful one with great achievements and contributions in many fields. She was a much-loved teacher, mentor and a leader who was a steadfast pillar of public health in Sri Lanka.

1968 Graduated from the University of Ceylon

1970 Began her professional life as an academic at the Department of Community Medicine, Faculty of Medicine, University of Colombo

1973 Obtained Diploma in Tropical Public Health from University of London

1976 Obtained PhD in Public Health Nutrition from University of London

1984-2005 Served as Head of the Department of Community Medicine

1992-2000 Chaired the Board of Study in Community Medicine of the Postgraduate Institute of Medicine, University of Colombo

1993-1999 Chaired the Research \& Higher Degrees Committee in the Faculty of Medicine and served as a member of the Planning and Development Committee and Board of Management of the Development Studies Institute of the University of Colombo

1996-1997 Was the Founder President of the College of Community Physicians of Sri Lanka

2005-2008 Served as Dean of the Faculty of Medicine, University of Colombo reflecting her versatile leadership qualities

2010

Retired from academic career as the Chair and Senior Professor of Community Medicine in the Faculty of Medicine, University of Colombo

Professor Fernando was a dedicated and conscientious teacher who has taught generations of undergraduate and postgraduate students in Community Medicine. The seeds of public health that she sowed during her forty-year 
career in academia have grown to become public health specialists in the country to carry the torch forward, a reflection of her meaningful life in science. As a much-respected teacher, she generated enthusiasm, passion and critical thinking among hundreds of her students. These attributes have helped shape the career of many medical professionals currently excelling in public health related disciplines in the island and beyond. This is testimony of her diverse capabilities towards bringing Sri Lankan medical education to greater heights.

She worked untiringly to uplift Community Medicine as a vital specialty in the fabric of Sri Lankan medical specialties. While laying this foundation, she gave leadership to commence the Physiotherapy Degree Programme during her tenure as Dean of the Faculty of Medicine, University of Colombo.

She had an outstanding track record in research across a broad range of themes, particularly infant \& young child nutrition especially in under-privileged populations, childhood injuries, maternal health, teenage pregnancy, overweight $\&$ obesity in urban sector, and access and quality of healthcare in rural settings. She has contributed immensely towards translating public health evidence into practice and policy in Sri Lanka. In recognition of her work, she had been the recipient of prestigious awards for excellence in teaching and research as well as fellowships, including those from the Sri Lanka Medical Association, National Academy of Sciences and the College of Community Physicians of Sri Lanka(CCPSL).

Professor Fernando had given leadership to several professional associations, CCPSL, Sri Lanka Association for the Advancement of Science (SLAAS), Nutrition Society of Sri Lanka and Sri Lanka Association of Community Medicine. Her varying capacities are demonstrated amply by the services she had rendered in national and international committees of the Ministry of Health, Sri Lanka, WHO, UNFPA, World Bank, USAID, SIDA and UNICEF. Her contributions to several advisory groups in the Ministry of Health for health policy and strategic development have been commendable.

Professor Fernando was indeed one among the luminaries in the field of Community Medicine in Sri Lanka. Her dedication, attention to detail and the practical outlook she had with persons from all walks of life, made her an outstanding member of the medical profession. Above all, she had a remarkable personality and was known for being a considerate and compassionate human being. Her contribution to the nation until her demise demonstrates the genuine altruism towards boosting public health in the country. She will always be fondly remembered, and her footprints will be reflected in the public health system of Sri Lanka. 